\title{
MENDORONG PEMAHAMAN KRITIS TENTANG DOKUMEN-DOKUMEN PRINSIPIL DAN NARASI KEBIJAKAN LUAR NEGERI AMERIKA DI KAWASAN ASIA PASIFIK 2000-2010: CATATAN PENELITIAN
}

\author{
Suzie Sudarman
}

\begin{abstract}
This research note essentially highlights how an argumentation was developed to reveal the implicit tensions that had been part of the American foreign policy maneuvers in Asia-Pacific, and the locus that were expressed have caused controversy. The finding is an effort to formulate analysis of the American foreign policy through an understanding of the nature of paradoxal and tension in the general American foreign policy, specifically in Asia-Pacific. Moreover, the pressures from outside the Asia-Pacific region, have eventually impacted the configuration of the publik officers and the experienced politicians in the locale, who have resulted policies to support the establishment of the relevant institutions in the region.
\end{abstract}

\section{Keywords}

Implicit tensions, maneuvers, locus, paradoxal, configuration.

\begin{abstract}
Abstrak
Catatan penelitian ini pada hakikatnya ingin menunjukkan bagaimana sebuah argumen dikembangkan untuk mengungkap adanya tensi implisit yang terkandung dalam seluruh manuver politik luar negeri AS di Asia-Pasifik dan lokus-lokus dimana tensi tersebut tidak dapat tertahankan sedemikian rupa sehingga muncul dan menimbulkan kontroversi. Pengungkapan ini merupakan usaha untuk memformulasikan analisis kebijakan luar negeri yang mampu memahami natur paradoksal dan tensi tak terelakkan dalam seluruh kebijakan luar negeri, dalam hal ini kebijakan AS di Asia-Pasifik. Lebih spesifik lagi adalah bahwa tekanan dari luar kawasan Asia Pasifik apabila diwujudkan dalam konfigurasi para pejabat publik dan para pelaku politik yang berpengalaman tentang perilaku AS secara nyata akan menghasilkan kebijakan yang bisa mendorong sebuah proses penguatan institusi yang relevan bagi kawasan tersebut.
\end{abstract}

\section{Keywords}

Tensi implisit, manuver, lokus, paradoksal, konfigurasi.

\section{PENDAHULUAN}

Kedaulatan adalah suatu paradoks: di satu sisi, adalah mustahil bagi negara untuk mampu benar-benar menancapkan seluruh kekuasaan di suatu wilayahnya sedemikian rupa sampai menundukkan semua yang ada dalam wilayah kedaulatannya ke dalam 
satu suara yang bulat; di sisi lain, negara selalu bertindak seolah-olah kemustahilan untuk benar-benar berdaulat tersebut adalah kenyataan yang sama sekali tidak relevan bagi dirinya. ${ }^{1}$ Berbagai hal dilakukan untuk menghapus tanda-tanda inkonsistensi dan kegegaran kedaulatannya. Hal ini berlaku untuk setiap negara, tak terkecuali sang adidaya Amerika Serikat (AS). Penelitian ini pertama-tama diselenggarakan untuk menunjukkan kegegaran kedaulatan AS ini.

Henry Kissinger yang selalu menekankan bahwa "foreign policy begins when domestic politics ends." Dari diktum ini dapat dirasakan jelas bahwa seluruh manuver politik luar negeri dilakukan saat tarik-menarik formulasi manuver tersebut di domestik selesai, atau setidaknya disudahi. Implikasinya, manuver/kebijakan luar negeri adalah cerminan dari politik domestik suatu negara. Apa yang dikatakan pemimpin negara/diplomateksekutor politik luar negeri-merupakan apa yang dikatakan oleh masyarakatnya. Asumsi implisit dari diktum ini tak lain adalah integritas (completeness), kestabilan dan ketakterbantahkannya suatu politik luar negeri. Melalui politik luar negeri ala Kissinger, suatu negara tampil dalam panggung dunia sebagai suatu entitas tunggal.

Kedaulatan AS atau, yang oleh karena predikat adidayanya bisa disebut sebagai, kedigdayaan, juga menderita hal serupa. Kegegaran kedaulatan ini nampak pada fenomena yang terjadi belakangan, yaitu saat situs whistle-blower WikiLeaks membeberkan banyak dokumen rahasia AS yang selama ini berstatus rahasia. Melalui "pembocoran" (leaking) dan publikasi bocoran tersebut, seluruh rationale atau justifikasi retorik kebijakan luar negeri AS terbukti palsu. Jargon-jargon universal mulia seperti perdamaian, demokrasi dan kebebasan, oleh WikiLeaks, diubah menjadi tak ubahnya topeng cantik untuk menutupi motivasi negatif AS di seluruh dunia-mulai dari Irak, Afghanistan, Palestina, Kosovo, dan Asia Pasifik. Arti penting WikiLeaks di sini adalah bahwa aktivitas ilegalnya tersebut menunjukkan bahwa kebijakan luar negeri suatu negara, bahkan AS sang adidaya, tidaklah manunggal dan integral. Implikasi teoritisnya, seluruh teorisasi yang mengatributkan predikat stabil, tak terbantahkan, dan murni refleksi politik domestik bagi suatu kebijakan luar negeri, menjadi runtuh dan tak dapat dipertahankan.

Memetik pelajaran dari fenomena WikiLeaks ini, dapat dilihat suatu paradoks dalam suatu formasi kebijakan luar negeri, yaitu di satu sisi bahwa ketegangan dan ketidakselesaian proses domestik-menyitir Kissinger-suatu politik luar negeri adalah hal yang tidak terelakkan, namun demikian di sisi lainnya, ketegangan ini haruslah diletakkan "di bawah karpet" atas nama suatu jargon yang disebut "kepentingan nasional." ${ }^{2}$ Hal ini kemudian tidak berarti bahwa ketegangan ini hilang begitu saja sekali dan selamanya saat politik luar negeri dicetuskan atau dieksekusi. Jauh dari anggapan ini, sisa-sisa tensi ini masihlah ada. Ia

\footnotetext{
1 Hizkia Yosie Polimpung, Psikoanalisis Paradox Kedaulatan Kontemporer, Thesis Magister Departemen Hubungan Internasional-UI, 2010

2 Bay of Pigs, Gulf War, Iraq invasion.
} 
terus menyertai kiprah eksekusi politik luar negeri ini. Adalah tensi ini yang oleh WikiLeaks mampu dimunculkan ke permukaan dan serta-merta, meminjam istilah Slavoj Zizek, "mengkorsletkan" seluruh formasi kebijakan luar negeri AS.

Concern utama penelitian ini adalah kebijakan luar negeri AS di Asia Pasifik. Hal ini berdasarkan beberapa analisis lingkungan strategis (lingstra) bahwa kawasan Asia Pasifik merupakan kawasan mulai dari mana Indonesia berpotensi memainkan peran signifikan di politik global, sekaligus secara timbal balik, kawasan yang dinamika di dalamnya memiliki pengaruh yang bisa jadi paling langsung berdampak pada kepentingan Indonesia. ${ }^{3}$ Faktor utama yang ada di balik anggapan ini adalah apa yang belakangan ramai disebut-sebut sebagai the rise of China. Cina adalah kekuatan yang bisa dibilang paling utama di kawasan. Hal ini, dari perspektif AS, sang adidaya, adalah "kerikil" yang sangat mengganggu kiprahnya di kawasan. Pertemuan antara AS dan Cina di Asia Pasifik inilah yang menjadi sumber dari hampir seluruh dinamika politik kawasan. Suatu analisis yang mampu melakukan debunking terhadap manuver-manuver kedua negara tersebut-AS dan Cina - adalah penting dan mendesak apabila, misalnya, Indonesia ingin dapat merumuskan kebijakan luar negeri yang obyektif tanpa jatuh pada jebakan buaian retorik manis keduanya di kawasan. Demi kepentingan penelitian ini, fokus akan ditujukan pada AS saja.

\section{LINGKUP PENELITIAN}

Secara teoritis penelitian ini akan menantang dua buah asumsi. Yang pertama adalah bahwa telah lazim untuk menggambarkan bahwa abad informasi ini layaknya sebagai revolusi besar dalam sejarah, yang akan mendorong lahirnya tindakantindakan dalam hubungan internasional dan dengan demikian juga bahwa apa yang turut membentuk jalannya sejarah adalah bagaimana seseorang itu menganalisanya. Karena perang informasi yang berlaku melampaui kemampuan seseorang untuk mengevaluasinya, timbul kesenjangan antara informasi dan pengetahuan dan selebihnya antara pengetahuan dan kebijaksanaan (wisdom). Yang kedua pada dasarnya berkenaan dengan sebuah argumen bahwa sekalipun pergulatan munculnya masyarakat sipil sangat terdiferensiasi dalam proses sejarah perkembangan institusi sosiopolitik, dalam kenyataannya pejabat-pejabat publik Amerika Serikat bisa memainkan peranan yang lebih aktif dalam transformasi identitas yang resisten atau memproyeksikan identitas yang terlegitimasi yang memupuk vitalitas masyarakat sipil dan negara. ${ }^{4}$

Dengan kata lain, dengan melihat ke belakang pada masa tersebut dan menjelajahi

\footnotetext{
3 The Jakarta Post Tuesday, Mustaqim Adamrah and Abdul Khalik, "RI Optimistic About UNSC Permanent Seat," The Jakarta Post, 28 December 2010.

4 Manuel Castells, The Power of Identity. The Information Age, Economy, Society, and Culture (Blackwell Publishers, 1997); Merlyna Lim, "Cyber-Civic Space in Indonesia. From Panopticon to Pandemonium?" in International Development Planning Review 24, no. 4 (2002): p.383-400.
} 
kebijakan Amerika Serikat, dapatkah kita menjumpai bukti nyata yang menunjukkan adanya kesan dan pesan kebijakan luar negeri Amerika Serikat yang konsisten? Ataukah justru kita memperoleh kesan bahwa kebijakan luar negeri itu lebih bersifat "contingent," "ad hoc," dan bergantung pada keadaan? Apakah kesan itu merefleksikan perubahan dunia? Pertanyaan-pertanyaan semacam ini semakin penting setelah terjadinya peristiwa 9/11/2001.

\section{SIGNIFIKANSI PENELITIAN}

Pertama, signifikansi akademis. Dengan melihat respon AS terhadap tensi di dalam negeri akibat paradoks kedaulatannya, yakni untuk menutupi tensi tersebut agar kebijakan luar negerinya dapat terlihat seolah-olah stabil, akan tampak jelas apa yang harus dilakukan negara-negara kawasan Asia Pasifik untuk menanggulangi hal-hal yang acapkali diakibatkan oleh sebuah interaksi dengan negara adidaya, seperti Amerika Serikat. Hal ini penting untuk kemudian dapat memberikan rekomendasi soal institusi mana yang dianggap penting untuk dibangun atau diperkokoh dalam menghadapi era global. Kedua, signifikansi teoretis. Tidak seperti teorisasi-teorisasi pada umumnya yang mempostulatkan kemanunggalan dan integritas kedaulatan dan kebijakan luar negeri, penelitian ini berupaya memberikan kontribusi teoretis yang mengikutsertakan berbagai aspek yang lalai dikaji dalam upaya memahami kebijakan luar negeri Amerika Serikat, yakni adanya dimensi disintegritas dan tensi tak terelakkan yang implisit dalam seluruh kedaulatan dan kebijakan luar negeri. Afirmasi ini kemudian menjadi landasan untuk memahami dan memformulasikan kembali konsekuensi dari ketegangan tersebut bagi negara-negara yang mungkin menjadi sasaran kebijakan luar negeri Amerika Serikat dan pada akhirnya yang melanjutkan upaya teorisasi soal kebijakan luar negeri Amerika Serikat mampu memahami dan mengkonseptualisasikan lebih lanjut bagaimana tensi tersebut ditutup-tutupi bahkan berupaya dilenyapkan oleh negara demi suatu kebijakan luar negeri yang konsisten. Ketiga, signifikansi dari aspek terapan. Setelah terjadi pendalaman melalui upaya penelitian ini, khususnya soal kegegaran kedaulatan dalam implementasi kebijakan luar negeri Amerika Serikat dengan memanfaatkan proses sosialisasi hasil penelitian diupayakan untuk membentuk dimensi terapannya bagi pelaksanaan kebijakan luar negeri Indonesia.

\section{STUDI LITERATUR}

David Lake mengkonseptualisasikan bahwa sejarah diplomasi Amerika Serikat mencakup tiga hal utama yang menjadi perhatiannya dan dianggap paling berpengaruh kepada politik luar negeri Amerika Serikat yaitu: ${ }^{5}$ seberapa besar keuntungan yang

5 David A. Lake, Entangling Relations. American Foreign Policy in Its Century (Princeton, N.J.: Princeton University Press, 1999). 
bisa diperoleh dari sebuah kerja sama? Apakah mitranya bisa diandalkan? Seberapa efektifkan aturan institusional alternatif dalam mengurangi kesempatan? Teori yang dikembangkan oleh David Lake paling dekat dengan institusionalisme liberal namun ia berbeda dalam beberapa hal yang penting. Pertama-tama, ia mengasumsikan bahwa oportunisme merupakan masalah utama yang akan membatasi kerja sama. ${ }^{6}$ Asumsi kedua adalah bahwa hubungan keamanan--sama dengan institusi dalam definisi yang luas - adalah instrumen pengawasan (instruments of control). Ada regimes "coordination" dan "collaboration." Asumsi ketiga bahwa karena pemaksaan selalu mungkin saja terjadi maka kerja sama itu selalu tidak mungkin menjadi efisien secara Pareto (Pareto efficient). ${ }^{7}$

Regime kolaborasi menyangkut organisasi internasional yang mengumpulkan dan menyebarluaskan informasi dan aneka prosedur yang memastikan para pelaku bahwa yang lainnya tidak akan berbuat curang. ${ }^{8}$ Regime koordinasi secara kontras bisa berlangsung tanpa mekanisme kepatuhan (compliance mechanisms): solusi kerjasama berlaku dengan sendirinya (self-enforcing). Organisasi internasional relevan pada saat regime belum terbangun (pre-regime) guna menyiapkan fora negosiasi yang penting. Beberapa struktur institusional yang formal mungkin juga fungsional dalam taraf setelah regime terbentuk. ${ }^{9}$

Kelemahan penjelasan tentang regime internasional membuka jalan bagi serangan perlawanan kaum realis di akhir tahun 1980an. Misalnya, John Mearsheimer and Joseph Grieco yang berargumentasi tentang perhatiannya soal keuntungan relatif (relative-gains) yang mencegah negara bekerja sama.

Mearsheimer (1994/1995) mendefinisikan institusi sebagai berikut. ${ }^{10}$

Sebuah rangkaian aturan yang menstipulasi cara-cara negara bekerja sama dan bersaingan satu dengan lainnya. Aturan ini menentukan bentuk-bentuk kerja sama yang bisa diterima, dan membatasi prilaku yang kurang dapat diterima. Aturan-aturan ini dinegosiasikan oleh Negaranegara, dan menurut beberapa orang teoritisi yang terkenal, hal ini mencakup penerimaan bersama atas norma-norma yang merupakan standar prilaku yang didefinisikan sebagai hak dan kewajiban. Aturan-aturan ini biasanya diformalisasi dalam perjanjian internasional, dan termanifestasi dalam organisasi-organisasi yang memiliki pegawai dan anggaran. Sekalipun aturan-aturan biasanya disertakan dalam organisasi internasional yang formal yang memaksa negara-negara untuk mematuhi aturan-aturan yang dibentuk. Institusi-institusi bukanlah sebuah bentuk pemerintahan dunia. Negara-negara harus memilih untuk mematuhi aturan-aturan yang telah diciptakan. Singkatnya, institusi meminta kerja sama negara-negara berdaulat untuk secara individu bekerja sama tanpa adanya mekanisme komando yang efektif.

\footnotetext{
${ }^{6}$ Ibid.

7 Ibid.

${ }^{8}$ Andreas Hasenclever, Peter Mayer and Volker Rittberger, Theories of International Regimes (CambridgeUniversity Press, 1997).

9 Ibid.

10 John J. Mearsheimer, "The False Promise of International Institutions," in International Security 19, no.3 (Winter 1994/95): p.5-49.
} 
Sebagai respons dari tantangan kaum realis, para ilmuwan kembali kepada model domestik yang mengusulkan pertanyaan-pertanyaan baru dan pendekatan-pendekatan baru tentang studi institusi internasional. Lisa Martin dan Beth Simmons melihat potensi yang sangat besar untuk melihat kembali teori-teori institusi-institusi domestik yang berakar pada teori permainan yang "non-cooperative."11 Asumsi yang mendasar adalah bahwa pelaku cenderung rasional, berpikir strategis, oportunistik, dan tidak ada seorang pelaku pun yang akan memaksakan berlakunya (enforce) sebuah kesepakatan. ${ }^{12}$

Jelas bahwa ketika perdebatan antara kelompok realis dan institusionalis telah tereduksi menjadi sekadar apakah institusi itu penting atau tidak, tampak kurang adanya perhatian terhadap mekanisme dimana efek institusional diharapkan akan terwujud. Institusionalis lebih cenderung melihatnya sebagai variabel independen. ${ }^{13}$ Negara memilih institusi karena akibat yang wujud dari kehadirannya, namun setelah terkonstruksi, institusi akan menahan dan membentuk prilaku. ${ }^{14}$ Sebagaimana dikatakan G. John Ikenbery bahwa kekuasaan Amerika itu menjadi lebih dapat diterima oleh negara lainnya karena terinstitusionalisasi. ${ }^{15}$

Dalam esai lainnya Ikenberry menjelaskan bahwa tawar-menawar yang berlangsung dan institusi yang tercipta pada awal masa hegemoni Amerika tidak hanya sekadar bertahan dalam kurun waktu lima puluh tahun, namun tampaknya juga berakar dalam struktur politik dan masyarakat negara-negara yang berpartisipasi di dalam orde tersebut, yakni lebih banyak orang beserta aktivitasnya terkait dengan institusi serta beroperasinya orde hegemoni liberal Amerika Serikat. Akibatnya mereka merasa menjadi bagian - atau memiliki kepentingan yang tertanam atau terus berlangsungnya sistem tersebut. ${ }^{16}$

Model "agenda setting" adalah model paling mutakhir berkaitan dengan analisis kebijakan luar negeri yang menyediakan pengetahuan yang dalam tentang soal keamanan nasional dan pembuatan kebijakan politik luar negeri. Atau dengan secara lebih spesifik lagi, Michael J. Mazarr melihat bahwa konsep seperti komunitas kebijakan (policy communities), peristiwa yang terfokus (focusing events), dan terbukanya kemungkinan membuat sebuah kebijakan (policy window) bisa membantu menjelaskan

\footnotetext{
${ }^{11}$ Lisa L. Martin and Beth A. Simmons, "Theories and Empirical Studies of International Institutions," in International Organization 52, no. 4 (Autumn 1998): p.729-757.

${ }^{12}$ Ibid.

${ }^{13}$ Lisa L. Martin and Beth A. Simmons, "Theories and Empirical Studies of International Institutions."

${ }^{14}$ Ibid.

${ }^{15}$ G. John Ikenberry, After Victory: Institutions, Strategic Restraint, and the Rebuilding of Order After Major Wars (Princeton, N.J.: Princeton University Press, 2001).

${ }^{16}$ G. John Ikenberry, "Liberal Hegemony and the Future of American Postwar Order," in eds., T.V. Paul and John A. Hall, International Order and the Future of World Politics (New York: Cambridge University Press, 1999).
} 
mengapa pemerintahan Bush memutuskan untuk berperang. ${ }^{17}$

Studi literatur ini mengupayakan pemahaman kritis tentang dokumen-dokumen prinsipil dan narasi kebijakan luar negeri Amerika di kawasan Asia Pasifik pada 20002010. Dalam kaitannya dengan kebijakan luar negeri Amerika Serikat, Bruce Cumings menegaskan bahwa sejarawan sebagai perekam sumber-sumber primer, atau sejarah bukan sebagai 'a pursuit of truth' namun lebih kepada 'the pursuit of truth,' masih sangat berperan dalam banyak departemen sejarah. Ia membahas hal ini dan banyak memberikan klaim tentang kebenaran secara panjang lebar. Ia berargumen bahwa sejarah dengan huruf besar S atau "history with a capital $\mathrm{H}$ is not truth but a descent through various interpretations." 18

Dengan memanfaatkan gambaran MacIntyre tentang metode Nietsche untuk mencari kebenaran melalui genealogy, ia secara cermat membedakan antara yang tidak bisa dibayangkan atau "the imponderables" dengan yang bisa dipahami atau "the ponderables (real) thought." Teka teki seperti ini adalah sumber untuk sebuah interpretasi sejarah. Dengan mengutip argumen Foucault tentang "discourse," ia menegaskan bahwa mungkin kebenaran itu harus ditelisik melalui struktur prediscursive," atau suatu hal yang ada sebelum kita memahaminya melalui bahasa ataupun interpretasi (something prior to language and interpretation). ${ }^{19}$

\section{STATE OF THE ART}

Penelitian ini mengambil latar pada studi-studi kebijakan luar negeri, dalam hal ini analisis politik luar negeri (FPA-foreign Policy Analysis). Sumbangsih yang diberikannya adalah dalam hal menyediakan cara baru dalam memahami kebijakan luar negeri suatu negara, khususnya AS di Asia-Pasifik. Tidak seperti teorisasi-teorisasi pada umumnya yang mempostulatkan kemanunggalan dan integritas kedaulatan dan kebijakan luar negeri, penelitian ini berupaya mereformulasikan suatu teorisasi yang pertama-tama mengafirmasi dis-integritasi dan tensi tak terelakkan yang implisit dalam seluruh kedaulatan dan kebijakan luar negeri. Afirmasi ini kemudian diteruskan untuk memahami dan meformulasikan ketegangan tersebut, dan pada akhirnya, mampu memahami bagaimana tensi tersebut ditutup-tutupi bahkan berupaya dilenyapkan oleh negara demi suatu kebijakan luar negeri yang konsisten.

\footnotetext{
${ }_{17}$ Michael J. Mazarr, “The Iraq War and Agenda Setting," in Foreign Policy Analysis 3, i 1 (January 2007): p.1-23.

18 Bruce Cumings, "'Revising Postrevisionism,' or The Poverty of Theory in Diplomatic History," in Diplomatic History 17, no. 4 (Fall 1993): p.539-569.

${ }^{19}$ Ibid.
} 


\section{Elemen yang tidak Harmonis dalam Sistem Politik Amerika}

Karya Kevin Phillips American Theocracy: The Peril and Politics of Radical Religion, Oil, and Borrowed Money in the $21^{\text {st }}$ Century ${ }^{20}$ berargumen bahwa tindakan "imperial" yang salah di masa lalu mengungkapkan adanya lima gejala kritis dari sebuah proses pembusukan, yang masing-masingnya di simulasi oleh agama. Adanya ketidakpuasan yang dirasakan bersama terhadap budaya populer; meningkatnya semangat keagamaan, eratnya hubungan agama-negara, atau munculnya impuls untuk melakukan perombakan (crusading impulse); meningkatnya komitmen kepada agama dengan mengorbankan akal sehat dan ilmu; munculnya gerakan milenial yang populer (popular millennialism); munculnya keangkuhan diplomatis dan militer. Andrew Kohut dan Bruce Stokes mencirikan sejarah Amerika sebagai sesuatu hal yang secara periodik bercirikan sebuah ekspansi dari pengaruh agama terhdap politik yang diasosiasikan oleh sebuah kebangkitan akbar (great awakenings) di mana kehadiran kelompokkelompok agama secara publik meningkat secara dramatis. ${ }^{21}$ Kebangkitan pertama terjadi bersamaan persis dengan masa kolonial, kebangkitan kedua menyumbang secara langsung kepada perang saudara, kebangkitan ketiga terjadi di masa abad k esembilan belas dan kedua puluh (19 $9^{\text {th }}$ and $20^{\text {th }}$ centuries) dan dialami semasa prohibisi dan gerakan untuk memperjuangkan hak pilih kaum perempuan, di dalam gerakan antikomunisme, gerakan hak sipil, dan protes terhadap berlangsungnya Perang Vietnam (prohibition and women's suffrage movement, within the anti-Communist crusade, the civil rights movement, and protests against the Vietnam war) dan kebangkitan di masa kini atau bergolaknya semangat keagamaan di Amerika pada dasarnya merepresentasi kebangkitan keempat. ${ }^{22}$

Sebagai kontrasnya adalah pandangan Samuel Huntington bahwa hubungan yang tidak mudah antara nilai-nilai Amerika dan institusi-institusi politik Amerika atau adanya kesenjangan antara orientasi normatif dan praktek yang mendorong lahirnya sebuah ketidakharmonisan dan upaya upaya untuk melancarkan sebuah kekuatan moralistik untuk mereformasi institusi-institusi Amerika. ${ }^{23}$ Dalam berbagai periode dalam sejarahnya Amerika telah berupaya untuk menghapuskan kesenjangan antara idealisme dan institusi-institusinya. Para pemimpin revolusi Amerika di tahun 1760-an dan 1770-an lah yang pertama-tama mengartikulasikan keyakinan Amerika (the American Creed) secara nasional. Konsensus yang dicapai di masa itu berkenaan dengan nilai-nilai liberal, demokratis, individualistik, dan egaliter. Kemudian hal ini berkembang melalui

\footnotetext{
${ }^{20}$ Kevin Phillips, American Theocracy: The Peril and Politics of Radical Religion, Oil, and Borrowed Money in the $21^{\text {st }}$ Century (New York: Viking, 2006).

${ }^{21}$ Andrew Kohut and Bruce Stokes, America Against the World. How We Are Different and Why We Are Disliked (New York Times Book, 2006), p.95.

${ }^{22}$ Ibid., p.95-96.

23 Samuel P. Huntington, American Ideals versus American Institutions," in ed., G.J. Ikenberry, American Foreign Policy. Theoretical Essays, Third Edition (New York: Longman, 1999), p.221.
} 
sentakan reformasi kaum Jacksonian di tahun 1820-an dan 1830-an, masa kaum Progresif (the Progressive era) dari tahun 1890-an hingga tahun 1914, dan reformasi moralistik (the moralistic reform) di tahun 1960-an dan awal 1970-an.

Dorongan pemerintah federal-baik di bawah kaum Republik dan Demokrat dalam periode antara tahun 1933 hingga 1980-untuk menasionalisasi satu pagu (standard) kebebasan dan keadilan bagi seluruh warga negara Amerika-akhirnya mengakibatkan munculnya beberapa isu panas (hot button issues) bagi segenap calon pemilih. Perubahan yang paling menonjol adalah upaya untuk memberikan pengutamaan kepada pemberian perlakuan yang setara bagi setiap etnis minoritas dan kaum perempuan di Amerika. ${ }^{24}$ Presiden Clinton juga secara halus menganjurkan warga Amerika untuk menerima kaum homoseksual sebagai warga Negara yang meiliki hak hak dasar untuk diperlakukan secara setara dalam perlindungan hukum. ${ }^{25}$ Kohut dan Stokes berargumen bahwa polapola pemilihan di dalam proses pemilihan presiden Amerika Serikat selama lebih dari empat dekade yang lalu telah menunjukkan bagaimana agama telah memainkan peranan yang meningkat terhadap bagaimana warga Amerika memilih dan menjadi alat prediksi yang lebih baik tentang sikap-sikap warga terhadap isu sosial, seksual, dan kultural. ${ }^{26}$

Misalnya adalah blok pemilih di tahun 1990-an yang dengan secara jelas terbelah antara kalangan yang mengutamakan soal penghasilan (pocketbook issues) dan mereka yang mementingkan soal kultural (cultural issues). ${ }^{27}$ Beberapa pemimpin agama telah memprotes berbagai upaya pemerintah untuk mengulurkan tangan (affirmative action) atau keputusan serta pemikiran politik pemerintah federal dengan jalan memberlakukannya telah menentang nilai-nilai Amerika yang tradisional (traditional values). ${ }^{28}$ Sebagai akibatnya isu sosial yang bertentangan dengan keyakinan keagamaan semakin tampak di lingkungan politik. Isu lainnya, seperti soal aborsi, perkawinan sesama jenis, riset sel punca (embryonic stem-cell research), abstinens seksual kalangan remaja (teenage sexual abstinence), pengungkapan secara publik simbol-simbol keagamaan (the publik display of religious symbols), pengajaran soal evolusi (the teaching of evolution) adalah isu-isu yang didorong oleh kekuatan keyakinan kaum Kristen konservatif (conservative Christian beliefs) telah memungkinkan semakin diterimanya di kalangan para pemilih kalangan penginjil serta Katolik konservatif (evangelical and conservative Catholic voters). Proses ini melibatkan pergulatan antaragama yang terorganisasi, yang akhirnya, menjadi pendukung agenda lainnya yang sedang diperjuangkan Presiden Bush. Selain Karl Rove dan Dick Cheney, kalangan lingkar dalam Presiden Bush tampaknya sangat

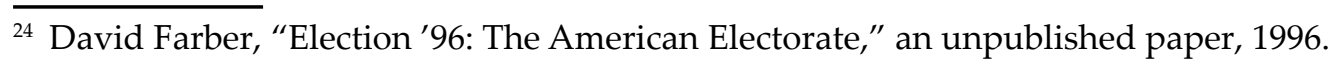

${ }^{25}$ Ibid., p.6.

${ }^{26}$ Kohut and Stokes, America Against the World., p.118.

${ }^{27}$ David Farber, “Election '96: The American Electorate,"p.6.

${ }^{28}$ Ibid.
} 
taat beragama. Kampanye Presiden Bush merupakan bukti adanya dimensi kaum konservatif yang berbelas kasihan (compassionate conservatism). Ada rancangan untuk memberikan bantuan dana pemerintah federal kepada kelompok-kelompok gereja yang melakukan layanan sosial atau apa yang dikenal dengan istilah "faith-based initiatives." Para analis kemudian menyimpulkan bahwa beralihnya para pemilih yang taat beragama ke partai Republik (GOP) memainkan peran yang besar dalam kemenangan Presiden Bush. Namun, secara ironis, meningkatnya dukungan pada Presiden Bush antara tahun 2000 hingga 2004 tampaknya lebih merefleksikan isu-isu keamanan nasional Amerika.

Untuk kebanyakan warga Amerika, transposisi kesenjangan idealisme dan institusi ini (this transposition of the ideals-versus-institutions gap) ke dalam kebijakan luar negeri seyogyanya merefleksikan, bukan hanya kepentingan nasional, namun juga nilainilai dan prinsip-prinsip politik yang mendefinisikan identitas Amerika. ${ }^{29}$ Persistensi kesenjangan idealisme dan institusi serta kebijakan Amerika telah menyediakan alasan dan membuka kesempatan dilancarkannya protes warga asing terhadap kontradiksi antara praktik dan idealisme Amerika yang diartikulasikan. Kalangan yang mengkritik warga Amerika semakin tampak sebagai kalangan di dunia yang secara universal dipandang sebagai kalangan intervensionis yang tidak populer (as the world universal unpopular busybody).

Di paruh kedua tahun 1990-an pandangan Amerika Serikat tentang dunia dari sebuah negara hegemoni yang baik (benign hegemony) telah bergeser menjadi sebuah negara adidaya yang arogan. Pemerintah Clinton tidak bertindak secara unilateral dalam soal yang berkenaan dengan penggunaan kekuatan militer, tetapi penggunaan otot Amerika Serikat dalam merubah perdagangan dan perekonomian dunia telah membuat Amerika Serikat sebagai kekuatan unilateralis. ${ }^{30}$ Sebagai seorang kandidat, Bush menjanjikan sebuah pendekatan yang rendah hati (humble) terhadap permasalahan dunia, namun Amerika Serikat terancam menggeser retorika dan pengambilan kebijakan untuk mendukung sebuah upaya pembangunan nasional (nation-building) yang terbesar sejak Perang Dunia II. ${ }^{31}$

Para pembuat kebijakan Amerika pun meluaskan fokus Perang Melawan Terorism (the war on terrorism) pasca 11 September dan hal ini mengakibatkan sikap anti-Amerika cenderung meningkat. ${ }^{32}$ Pemerintahan Bush mengupayakan proses demokratisasi yang lebih luas di Timur Tengah dan pemberian bantuan bagi korban Tsunami di Asia Selatan dan Tenggara telah diterima dengan baik. Namun, hanya di empat negara terjadi

\footnotetext{
${ }^{29}$ Huntington, American Ideals versus American Institutions," in ed., Ikenberry, American Foreign Policy, p.237.

${ }^{30}$ Meredith Woo-Cumings, unpublished manuscript, June 2004.

${ }^{31}$ Ibid.

${ }^{32}$ Kohut and Stokes, America Against the World, p.25.
} 
peningkatan opini publik tentang Amerika Serikat secara signifikan. ${ }^{33}$ Di Indonesia opini publik yang mendukung Amerika meningkat dua kali lipat antara tahun 2003 dan 2005, dari 15\% menjadi 38\%. Publik telah secara nyata mengekspresikan opini tentang warga Amerika yang menunjukkan penurunan sebanyak $10 \%$, dari 56\% menjadi $46 \%{ }^{34}$

Dalam pemilihan sela tahun 2006 partai Demokrat berkuasa meminta perubahan arah dari pelaksanaan perang di Irak, menjanjikan pembersihan pemerintahan untuk menciptakan kondisi perekonomian yang lebih baik bagi kalangan kelas menengah dan memastikan tersedianya obat-obatan yang murah bagi kaum lanjut usia. Menurut kalangan analis politik, kebanyakan kaum pemilih pada pemilihan umum lebih cenderung kepada isu nasional daripada lokal, dan kalangan independen yang merupakan 26 persen dari para pemilih nasional lebih merupakan konstituensi mengambang (the swing constituency). Secara nyata dan menyeluruh partai Republik berhasil mempertahankan basis kalangan agamanya. Kalangan pemilih penginjil berkulit putih (White evangelical-born again) memilih partai Republik sebesar 69 persen hingga 29 persen. Di tahun 2004, kalangan yang sama juga memilih partai Republik dalam pemilihan majelis rendah (House) dengan selisih suara yang lebih tinggi sedikit, 73 persen hingga 26 persen. ${ }^{35}$

Pemilihan sela Amerika Serikat tidak merefleksikan sebuah periode semangat keagamaan yang lazim (the usual period of creedal passion) yang didahului atau didampingi oleh sebuah kebangkitan akbar keagamaan (great awakening), yang terjadi adalah justru penyampaian pesan yang nyata dalam artian warga Amerika menginginkan para pemimpinnya di Washinton untuk mengesampingkan perbedaan partisan dan bekerja bersama untuk mengatasi berbagai tantangan yang dihadapi bangsa Amerika. Keberhasilan kalangan partai Demokrat lebih berkenaan dengan rasa kemarahan terhadap Presiden Bush dan Perang Irak.

\section{METODE RISET}

Dengan memfokuskan pada periode sebelum dan sesudah krisis 2008, penelitian ini dirancang dengan menggunakan pendekatan studi kasus historis dengan membandingkan berbagai studi dokumentasi serta narasi yang dilengkapi dengan upaya kontekstualisasi dengan bacaan lainnya dan monitoring kawasan, negara, dan isu tertentu. Hal ini dimaksudkan agar penelitian dapat menggunakan kombinasi beberapa metode pada saat melakukan analisa. Secara lebih lanjut, penelusuran proses secara historis akan mengidentifikasikan aktor-aktor sentral dalam pembuatan kebijakan politik luar negeri Amerika Serikat di kawasan Asia Pasifik untuk kemudian

\footnotetext{
33 Kohut and Stokes, America Against the World, p.27-28.

34 Ibid. 30.

35 “Exit Polls: Vote a repudiation of Bush, war in Iraq," CNN.com, accessed $8^{\text {th }}$ November 2006.
} 
membangun mekanisme kausal yang menghubungkan tekanan dari luar kawasan Asia Pasifik dengan berbagai strategi dan pilihan aktor-aktor tersebut.

Sementara itu, perbandingan antara dokumen prinsipil serta narasi kebijakan luar negeri Amerika Serikat dengan dokumen yang dibocorkan oleh WikiLeaks memungkinkan terciptanya pengetahuan baru tentang kebijakan luar negeri AS untuk dipelajari. Perbandingan dengan konteks bacaan yang lebih luas, yang dibarengi dengan upaya monitoring kawasan, negara, dan isu tertentu digunakan untuk menguji bahwa dalam implementasi kebijakan luar negeri Amerika Serikat terdapat variasi berdasarkan konteks kelembagaan dan politik di setiap negara yang diteliti. Dengan hasil perbandingan lintas dokumen dan bacaan, diharapkan bahwa penelitian ini akan menghasilkan suatu kesimpulan atas dasar penjelajahan serangkaian peristiwa diplomasi untuk kemudian memberikan rekomendasi tentang institusi mana yang dianggap penting untuk diperkokoh dalam menghadapi era global.

Pertanyaan penelitian yang utama adalah dalam kondisi yang bagaimanakah tekanan yang berasal dari luar kawasan Asia Pasifik berupa kebijakan luar negeri Amerika Serikat yang kurang dialogis, akan berhasil atau gagal? Secara lebih spesifik lagi, apa yang dilakukan oleh negara, dalam hal ini Amerika Serikat, untuk menutupi tensi yang bersumber dari paradoks kedaulatannya agar supaya kebijakan tersebut dapat terlihat seolah-olah stabil? Upaya-upaya seperti apa yang dilakukan oleh negara, dalam hal ini, AS dan mekanisme-mekanisme seperti apa yang terjadi di dalamnya? Dan faktor-faktor apa yang mempengaruhi sukses tidakya upaya tersebut? Apalagi ketika hal ini tampaknya mencapai puncaknya di tahun 2000-2008? Dan mengapa proses ini mengalami periode stasis atau mengalami pelambatan selama dan setelah terjadi krisis ekonomi 2008 ?

Kami menghipotesiskan bahwa Amerika Serikat tampil dalam panggung dunia sebagai suatu entitas tunggal melalui berbagai upaya menghapus tanda-tanda inkonsistensi dan kegegaran kedaulatannya. Secara lebih spesifik lagi, kami menghipotesiskan bahwa tekanan yang berasal dari luar kawasan Asia Pasifik apabila terwujud atau dilangsungkan ketika hadir konfigurasi para pejabat publik dan para pelaku politik yang berpengalaman tentang prilaku Amerika Serikat dapat akan menghasilkan kebijakan yang bisa mendorong proses penguatan institusi yang relevan bagi kawasan tersebut. Keseluruhan argumen di atas akan ditelaah lebih lanjut melalui proses sebagai berikut.

Selanjutnya hipotesis riset kami sesuaikan dengan konteks data yang ada dan kami ubah menjadi sebagai berikut, bahwa kestabilan kedaulatan AS adalah kestabilan brand AS sebagai guarantor yang dihasilkan/dijaga oleh negara-negara yang berpihak pada AS. Hipotesis ini jelas berbeda dengan hipotesis kami di awal, namun perubahan ini terjadi setelah kami melakukan analisis dari berbagai pemberitaan media dan jurnal yang dapat kami kumpulkan (Foreign Affairs, Washington Post, Jakarta Post, The New York Times, Pacific Service, dan sebagainya).

Dari media-media tersebut, ada dua poin penting yang dapat kami analisis. 
Pertama, bahwa masalah keamanan merupakan masalah prioritas AS di Asia Pasifik. Hal ini terlihat dari konsistensi pemberitaan masalah keamanan dari tahun 2000. Masalah ekonomi baru menjadi perhatian utama di tahun 2005. Alasannya sederhana, kekuatan ekonomi Cina, baik di kawasan maupun global sedang berada dalam posisi puncaknya terutama dalam pertemuan WTO. Sebenarnya dari tahun 2003, masalah bangkitnya ekonomi Cina sudah menjadi sorotan media namun AS belum menunjukkan sikap yang jelas (baik agresif maupun pasif) terhadap masalah ini. Bahkan di tahun 2004, Bush sempat menyatakan bahwa pendekatan AS terhadap Cina adalah "turning adversary into opportunity." Hal ini berubah setelah di tahun 2005 East Asia Summit diadakan tanpa adanya AS. Condoleeza Rice menyebut Cina sebagai "negative force."

Fokus pada masalah keamanan pun berubah seiring dengan dinamika kebijakan luar negeri AS. Sepanjang tahun 2000 hingga 2010, AS konsisten dengan terorisme sebagai perhatian utama kebijakan luar negerinya di Asia Pasifik, terutama di Asia Tenggara, sedangkan untuk kawasan Asia Timur, keamanan di semenanjung Korea (Korea UtaraKorea Selatan) masih menjadi perhatian yang utama. Di tahun 2006, masalah pengamanan selat Malaka sempat menjadi perhatian, namun tidak berlangsung lama.

Hal kedua yang menjadi perhatian kami adalah data WikiLeaks yang menjadi isu-isu di Asia Pasifik justru tidak "sebombastis" atau segegar data WikiLeaks yang berkaitan dengan isu-isu Timur Tengah. Justru hal-hal yang disorot dalam WikiLeaks tersebut merupakan hal-hal yang kurang signifikan, seperti masalah domestik, perilaku pejabat lokal, bahkan interaksi antara pejabat negara dengan aktor privat, baik di bidang perdagangan, kesehatan, maupun masalah-masalah keamanan. Hal ini menunjukkan karakteristik yang berbeda dengan kawat-kawat WikiLeaks yang lain. Bagi kami, perbedaannya tidak semata-mata pada tingkat kontroversinya, namun juga pada prioritas dan pendekatan AS terhadap negara-negara di kawasan Asia Pasifik.

Dua hal ini menunjukkan beberapa hal. Yang pertama, hipotesis yang telah dirumuskan di atas, yakni bahwa negara-negara di Asia Pasifiklah yang justru menjaga hegemoni AS dan tidak semata-mata kebijakan luar negeri AS saja. Justru dari berbagai kawat WikiLeaks yang telah kami baca, kami berasumsi bahwa kebijakan luar negeri dan diplomasi AS, pada dasarnya, mengakar atau bertumpu pada situasi kontekstual yang ada di Asia Pasifik untuk "mengamankan" terlaksananya kepentingan nasional AS melalui kebijakan luar negerinya. Namun pada sisi lain, kawat-kawat WikiLeaks juga menunjukkan sisi yang berbeda, yakni bahwa negara-negara di Asia Pasifik jauh lebih kompleks dibandingkan negara-negara di kawasan lain. Tidak hanya negara secara individu, tetapi juga kawasan Asia Pasifik sendiri merupakan sebuah entitas yang kompleks. Pada satu sisi, AS jelas sudah memiliki pengaruh, namun AS seakan sulit untuk mengontrol kawasan Asia Pasifik. Cina berhasil bangkit dan bermain dalam politik internasionalnya sendiri bahkan terbentuknya East Asia Summit seakan menunjukkan "kemandirian” Asia Pasifik di luar pengaruh AS. Namun analisa ini masih 
diuji dalam tahap dua kegiatan riset kami, yakni data analisis. Apabila dapat ditunjukkan usaha-usaha menuju "kemandirian" tersebut, yang harus ditemukan kemudian adalah bagaimana hal tersebut dilakukan dan apabila tidak bisa terbangun dengan bukti nyata usaha-usaha tersebut, yang harus ditemukan kemudian adalah bagaimana AS masih memegang kontrol atas pengaruh-pengaruhnya di Asia Pasifik.

\section{ANALISIS}

Belum pernah terjadi dalam sejarah bahwa suatu negara dapat memiliki sebuah dominasi, cakupan, dan pengaruh seperti apa yang dinikmati oleh AS di saat ini. Kekuasaan AS bukan sekadar terbatas pada dominasi militer, karena juga mencakup institusi yang menata kelola perekonomian global atau adanya kenyataan bahwa kekuasaan dan pengaruh AS juga turut menentukan alokasi arus kredit serta investasi internasional. Di samping itu pula, ada dampak budaya Amerika dan kekuasaan lunak (soft power). ${ }^{36}$ Amerika Serikat, dalam hal ini tidak seperti negara lainnya, memiliki kapasitas untuk mempengaruhi secara langsung maupun tidak langsung bagian dunia lainnya dalam berbagai tataran. ${ }^{37}$

Bruce Cumings menggarisbawahi lima elemen yang dipandang penting sebagai sumber kejayaan AS yang tidak ada kaitannya dengan kekuatan militernya yang sangat unggul, antara lain adalah konsumsi massa dan budaya massa, keberuntungan geografi berupa sebuah kontinen-memiliki kemajuan tehnologi-dan sebagai konsekuensinya terbentuknya kekhasan liberalisme AS dan hegemoni global. ${ }^{38}$ James Kurth mengatribusikan empat dimensi hubungan dunianya antara lain $^{39}$ (i) perekonomian yang terbesar dan termaju di dalam kerangka perekonomian global yang sekaligus menjadi kekuatan pendorong globalisasi; (ii) satu-satunya negara adidaya dan bahkan sebuah hyperpower; (iii) kekuatan militer berteknologi tinggi dan pemimpin sebuah revolusi di bidang militer (revolution in military affairs) dan (iv) contoh kekuasaan lunak (soft power) dan penyebarluasan budaya pop di seluruh dunia.

Kami menghipotesiskan bahwa kestabilan kedaulatan AS adalah kestabilan brand AS sebagai guarantor yang dihasilkan atau dijaga oleh negara-negara yang berpihak pada AS. Robert Rotberg mempostulasikan beberapa kriteria untuk menentukan status negara sebagai negara kuat, lemah, atau gagal. Bahwa negara lemah tidak terlampau berhasil atau secara tidak sempurna dapat menyediakan

\footnotetext{
${ }^{36}$ Mark Beeson, "Introduction," in ed., Mark Beeson, Bush and Asia. America's Evolving Relations with East Asia (London: Routledge, 2006).

${ }^{37}$ Ibid. p.x.

${ }^{38}$ Bruce Cumings, "Still the American Century," in Review of International Studies 25, i 05 (December 1999): p.275.

${ }^{39}$ James Kurth, "Globalization and Empire: The Effects of 9/11 and the Iraq War," in eds., Bruce Mazlish et al., The Paradox of a Global USA (Stanford: Stanford University Press, 2007), p.150.
} 
political goods seperti keamanan, membuka kemungkinan warga negaranya berpartisipasi sepenuhnya secara bebas dan terbuka, juga penyediaan perawatan kesehatan, sarana pendidikan, sarana umum lainnya dan infrastruktur yang dibutuhkan. ${ }^{40}$ Politik luar negeri dalam situasi yang demikian sudah barang tentu mencerminkan kelemahan. Masalahnya untuk membangun perekonomian dan keamanan dengan cara menggantungkan diri kepada bantuan serta investasi asing meningkatkan intensitas ketergantungan jangka pendek. ${ }^{41}$ Sebagian besar negara-negara di Asia Pasifik bisa diasumsikan sebagai mengalami kelemahan dalam beberapa dimensi tertentu sehingga menimbulkan apa yang disebutkan Weinstein sebagai dilemma of dependence.

Secara lebih spesifik lagi kami menghipotesiskan bahwa tekanan yang berasal dari luar kawasan Asia Pasifik apabila terwujud atau dilangsungkan ketika hadir konfigurasi para pejabat publik dan para pelaku politik yang berpengalaman tentang prilaku Amerika Serikat secara nyata akan menghasilkan kebijakan yang bisa mendorong proses penguatan institusi yang relevan bagi kawasan tersebut. Hal ini semakin menjadi penting di saat reputasi AS untuk berperilaku yang berkeadilan dan menjalankan kepemimpinannya ada pada titik terendah pasca terjadinya krisis keuangan Asia 1998 dan ketika peperangan yang dilaksanakan AS kian tampak dipedomani oleh sebuah strategi keamanan nasional, yang dengan jelas menyatakan bahwa dominasi wajib menjadi tujuan sebagaimana tertera dalam Defense Policy Guidance. Sehubungan dengan hal ini patut dicatat pandangn Robin Brown tentang karya Joseph Nye yang mengapropriasi Bachrach dan Baratz ${ }^{42}$ yang cenderung menyamarkan perbedaan antara pendekatan realis dan liberal dalam konsepsinya tentang kekuasaan, karena Nye menyatakan bahwa negara-negara patuh kepada orde hegemoni karena hal ini memenuhi kepentingan mereka. ${ }^{43}$ Padahal Bachrach dan Baratz secara kontras mengargumentasikan bahwa para elit menjaga dominasinya dengan jalan mencegah kelompok-kelompok yang kurang puas untuk dapat menyatakan pandangan mereka. Sekalipun penuh ambiguitas kekuasaan lunak (soft power) adalah salah satu konsep hubungan internasional yang secara luas diterima.

\footnotetext{
${ }^{40}$ Robert I. Rotberg (ed.), State Failure and State Weakness in a Time of Terror (Brookings Institution Press, 2003): p.1-25; Pinar Bilgin and Adam David Morton, "Historicising Representations of 'Failed States': Beyond the Cold War Annexation of the Social Sciences?," dalam Third World Quarterly 23; no. 1 (2002): p.55-80; David Carment, "Assessing State Failure:Implications for Theory and Policy," dalam Third World Quarterly 24; no. 3 (2003): p.407-427; Robert H. Dorff, "Failed States After 9/11: What Did We Know and What Have We Learned? " dalam International Studies Perspectives no. 6 (2005): p.20-34.

${ }^{41}$ Franklin B. Weinstein, Indonesian Foreign Policy and The Dilemma of Dependence. From Sukarno to Soeharto (Ithaca: Cornell University Press, 1976): p.33.

42 Peter Bachrach and Morton S. Baratz, "Two Faces of Power," in American Political Science Review 56, i 4 (Dec., 1962), p.947-952.

${ }^{43}$ Robin Brown, "Information Technology and the Transformation of Diplomacy," in Knowledge, Technology, \& Policy 18, no. 2 (Summer 2004): p.14-29.
} 
Sejak tahun 1990 Departemen Pertahanan AS menerbitkan laporan secara periodik outline dari strategi AS di Asia Pasifik. ${ }^{44}$ Dokumen lainnya, Asia 2025 menyimpulkan baik Cina yang kuat maupun yang lemah merupakan ancaman bagi kepentingan strategis AS. ${ }^{45}$ Sebuah studi lainnya dari Project for the New American Century (PNAC) berargumen bahwa grand strategy AS adalah berkenaan dengan pencapaian dan pelestarian kapabilitas militer yang unggul secara global baik untuk masa kini maupun untuk masa mendatang dalam mengamankan Asia menjadi bagian yang integral dalam cara pandang ini. Tentara AS harus diposisikan di Asia Timur dan Asia Tenggara untuk menjaga keamanan lalu lintas maritim di kawasan tersebut. ${ }^{46}$

Quadrennial Defense Review (QDR) selama masa pemerintahan Bush melihat Cina sebagai pesaing AS yang utama dan target yang hakiki untuk mewujudkan keunggulan strategis AS. ${ }^{47}$ Kepentingan tradisional AS meliputi hal: ${ }^{48}$ (i) mempromosikan stabilitas dan perimbangan kekuasaan dengan tujuan strategis menjaga Asia Tenggara dari dominasi hegemoni negara manapun; (ii) mencegah agar AS tidak dikucilkan dari kawasan oleh kekuatan lain ataupun sekelompok kekuatan lainnya; (iii) menjaga kebebasan navigasi dan perlindungan alur laut (sea lanes); (iv) menjaga kepentingan perdagangan dan investasi; $(v)$ mendukung sekutu berdasarkan treaty dan negara sahabat; (vi) mempromosikan demokrasi, aturan hukum, hak asasi, dan kebebasan beribadah. Pada intinya, adanya kepedulian AS atas tatanan regional Asia Timur (East Asian regional architecture) di bidang perekonomian dan keamanan adalah berkenaan dengan semakin meningkatnya kekuatan Cina. ${ }^{49}$

Presiden George W. Bush memang cenderung untuk lebih mengutamakan sebuah pertahanan yang kuat. Namun, sampai 11 September 2001, kebijakannya tidak banyak berbeda dengan Presiden Clinton. Setelah tragedi 11 September, Presiden Bush memfokuskan politik pertahanan dan luar negeri AS kepada war on terror. Tampak

\footnotetext{
${ }^{44}$ Department of Defense, A Strategic Framework for the Asian Pacific Rim: Looking Toward the 21 ${ }^{\text {st }}$ Century, 1990; A Strategic Framework for the Asian Pacific Rim, 1992; The East Asia Strategy Report,_1994; Report on Bilateral Defense Cooperation for the 21 $1^{\text {st }}$ Century, 1997; The United States Security Strategy for the East Asia-Pacific Region, 1998; Military Power of the People's Republik of China, Annual Report to Congress; The Quadrennial Defense Review, 1997; 2001; 2006, 2010.

${ }^{45}$ United States Under Secretary of Defense (policy), Asia 2025, Summer School Study (Newport, R.I.: U.S. Naval War College, 1999).

46 PNAC, Rebuilding America's Defenses, 2000.

${ }^{47}$ USDOD, Quadrennial Defense Review Report (2001) www.defenselink.mil/pubs/qdr2001.pdf juga lihat QDR lainnya tahun 1997, 2006, 2010

${ }^{48}$ Bruce Vaughn and Wayne M. Morrison, "China-Southeast Asia Relations: Trends, Issues, and Implications for the United States," Updated April 4, 2006 CRS Report for Congress RL32688 (Congressional Research Service, The Library of Congress, 2006): p.4; yang mutakhir adalah Dick K. Nanto, "East Asian Regional Architecture: New Economic and Security Arrangements and US Policy," September 18, 2006 CRS Report for Congress RL33653 (Congressional Research Service, The Library of Congress, 2006).

${ }^{49}$ Nanto, "East Asian Regional Architecture: New Economic and Security Arrangements and US Policy."
} 
kecenderungan unilateral dan adanya misi utopi sebagaimana dapat dibaca dalam pidato state-of-the-union-nya: "I also have this belief, strong belief that freedom is not this country's gift to the world. Freedom is the Almighty's gift to every man and woman in this world. And as the greatest power on the face of the earth we have an obligation to help the spread of freedom. ${ }^{50}$

Kebijakan pertahanan dan luar negeri pemerintahan Bush ditujukan untuk mencapai dan melestarikan posisi AS yang unik dalam hirarki global. AS sangat menggantungkan diri kepada kekuatan militer AS "full spectrum dominance," di udara, darat, maritim, dan ruang angkasa. ${ }^{51}$

Tidak terjadinya konfrontasi AS-China patut dicatat sebagai jasa (legacy) Presiden Bush yang telah mendorong China agar menjadi "stakeholder" yang absah dalam soal keamanan global. ${ }^{52}$ Presiden Bush hanya mampu secara minimal dalam kebijakan perdagangan, namun cukup inovatif dalam peningkatan dana untuk mencegah HIV, dan penciptaan Millennium Challenge Corporation untuk mendorong perekonomian di negara-negara sedang berkembang untuk segera mencapai ambang batas Investasi Langsung Penanam Modal Asing (foreign direct investment-threshold status). ${ }^{53}$

Namun, strategi raya (grand strategy) Wolfowitz atau yang dikenal juga sebagai Wolfowitz's Doctrine mengutamakan persiapan total jangka panjang (a long-term lock-in) melawan ancaman militer seperti yang dilancarkan negara adi daya, membutuhkan baik penggunaan preemptive war dan unilateralisme. Nosi bahwa primasi geopolitik AS dirawat melalui dominasi militer agak kurang serasi dengan apa yang tengah berlangsung di dunia saat itu yang penuh dengan kekisruhan sipil dan kekerasan etnis. ${ }^{54}$

Dengan terpilihnya Barack Obama, kesan dunia akan AS menjadi lebih baik. Dalam hal yang berkenaan dengan politik luar negeri Presiden Obama telah memiliki visi yang aktif, yaitu bahwa ia ingin memperbaiki citra AS di luar negeri, istimewa di negeri-negeri berpenduduk mayoritas Muslim; mengakhiri keterlibatan AS dalam dua peperangan; mengulurkan tangan ke Iran; memperbaiki hubungan dengan Rusia sebagai cara untuk menghapuskan senjata nuklir; mengembangkan kerja sama signifikan dengan China dalam soal-soal yang berkenaan dengan kawasan maupun global; dan menciptakan perdamaian di Timur Tengah. ${ }^{55}$ Presiden Obama ingin mewujudkan

\footnotetext{
50 Transcript: 2003 State of the Union Address.

${ }^{51}$ Diane K. Mauzy and Brian L. Job, “U.S. Policy in Southeast Asia. Limited Reengagement After Years of Benign Neglect," in Asian Survey XLVII, no. 4 (July/August 2007): p.629.

52 Thomas P. M. Barnett, Great Powers. America and the Wprld After Bush (New York: G.P. Putnam's Sons, 2009): p.8-9.

53 Ibid. p.10.

${ }^{54}$ Ibid. p.12-13.

55 Martin S. Indyk, Kenneth G. Lieberthal, and Michael C. O'Hanlon, Bending History. Barack Obama's Foreign Policy (Washington DC: Brookings Institution Press, 2012): p.1-2.
} 
sebuah orde global dengan Amerika tetap dalam posisi kepemimpinan, terutama dalam soal hard power namun semakin berbagi tanggung jawab serta beban dengan negaranegara lainnya. ${ }^{56}$

Pilar pertama dari orde global ini adalah sebuah perubahan dalam hubungan dengan negraaa-negara besar yang sedang bangkit di Asia seperti China dan India. Hubungan dengan Rusia juga akan dirubah (reset). Secara Presiden Obama akan lebih fokus ke diplomasi dan engagement. ${ }^{57}$ Pilar kedua adalah perlucutan senjata dan nonproliferasi. ${ }^{58}$ Pilar ketiga, adalah mengubah ketegangan hubungan dengan negaranegara berpenduduk mayoritas Muslim. ${ }^{59}$

Pada awalnya Presiden Obama memiliki dua tujuan kebijakan luar negeri lainnya yakni mencegah hancurnya perekonomian global seraya melindungi Amerika Serikat dari ancaman langsung. Di luar hal tersebut adalah menciptakan hubungan baik dengan China dan Rusia, mengawasi ancaman senjata nuklir, memperbaiki hubungan AS dengan negara-negara berpenduduk mayoritas Muslim. ${ }^{60}$

Sebelum dikonfirmasi sebagai Menteri Luar Negeri AS Hillary Clinton meletakkan dasar politik luar negeri AS yang baru yang mengupayakan sebuah kombinasi antara strategi diplomasi, ekonomi, militer, politik, hukum dan budaya. Dinyatakan bahwa politik luar negeri AS akan direalisasikan sebagai kekuatan cerdas (smart power) yang mengkombinasikan prinsip dan pragmatisme bukan sekadar mengutamakan ideologi. ${ }^{61}$

Di musim gugur 2009, pidato James Steinberg, seorang Wakil Menlu AS berargumentasi bahwa Cina perlu mengadopsi strategi untuk meyakinkan seluruh dunia bahwa semua telah siap untuk menerima kehadiran Cina yang kuat dan berperan di dunia tanpa merugikan keamanan dan kesejahteraan bangsa lain. Di bulan Januari 2010 Menteri Luar Negeri AS Clinton menyampaikan outline dari prinsip-prinsip yang akan mendefinisikan sikap dan tindakan AS di kawasan Asia Pasifik dan juga tentang pendekatan multilateral AS. (i) Paling mendasar adalah hubungan AS dengan sekutunya Jepang, Korea Selatan, Australia, Thailand, dan Philippines (The US alliance relationships with Japan, South Korea, Australia, Thailand, and the Philippines are the cornerstone of American regional involvement); (ii) Institusi kawasan dan uspaya harus berjalan sesuai dengan tujuan yang akan dicapai AS (Regional institutions and efforts should work to advance American clear and increasingly shared objectives); (iii) Institusi harus bersifat efektif dan terfokus pada pencapaian hasil. (The institutions must be effective and be focused on

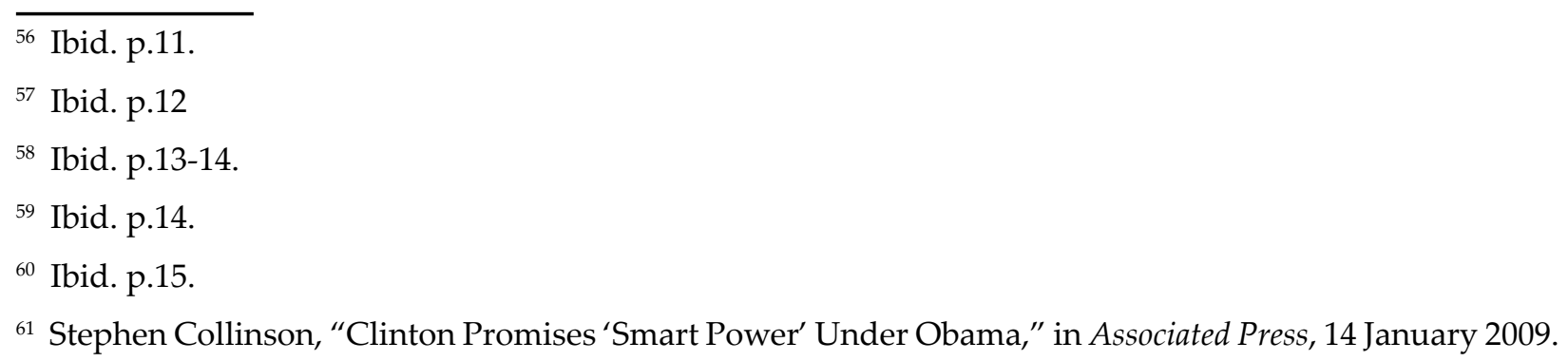


delivering results.); (iv) AS harus menjaga dan menjadi semakin fleksibel dalam mengejar tujuan yang dikejarnya. (The US must seek to maintain and enhance flexibility in pursuing the results it seeks.); (v) AS harus memutuskan sebagai sebuah bangsa Asia Pasifik institusi kawasan mana yang akan paling bisa melindungi dan mempromosikan seluruh masa depan kolektif bangsa (The US needs to decide, as Asia Pacific nations which will be the defining regional institutions that will best protect and promote the nations' collective future.)

Figure 1. Map of Strategic Straits of Southeast Asia

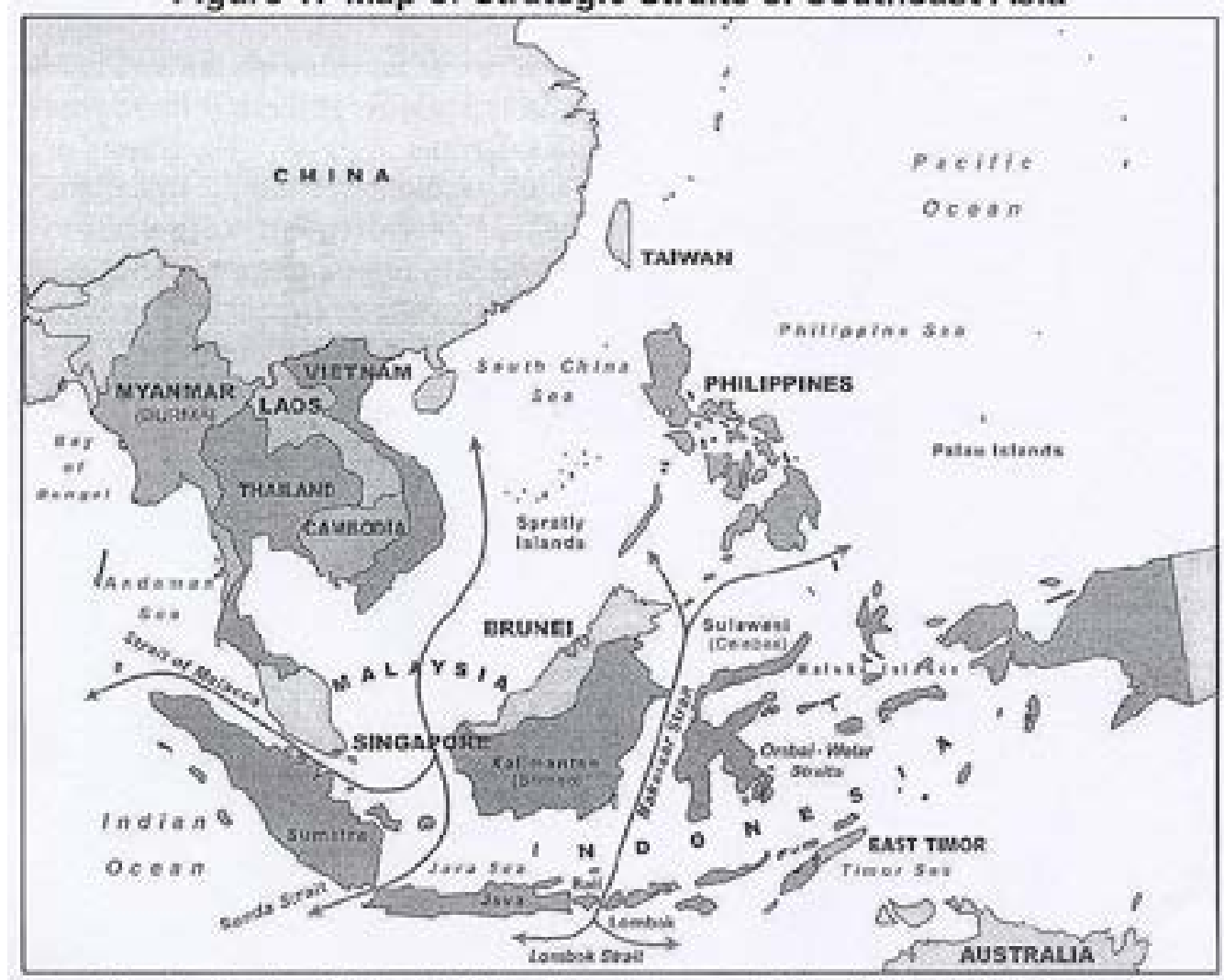

Source: Ktbrmation basad woon Chokepoints: Markine Economb Concems in Sewtheast Asta by John H. Noer wh David Gregory. Map Ressurees. Adepled by CRS (K. Yanoty 102304)

Map of Strategic Straits of Southeast Asia ${ }^{62}$

\section{BIBLIOGRAFI}

Bachrach, Peter and Morton S. Baratz, "Two Faces of Power," in American Political Science Review 56, i 4.1962.

Barnett, Michael and Raymond Duvall, "Power in International Politics," in International Organization 59 p.39-75. 2005.

Barnett, Thomas P. M. Great Powers. America and the Wprld After Bush New York: G. P. Putnam's Sons. 2009.

\footnotetext{
${ }^{62}$ Vaughn and Morrison, "China-Southeast Asia Relations: Trends, Issues, and Implications for the United States,": p.21.
} 
Beeson, Mark. "Introduction," in ed., Mark Beeson, Bush and Asia. America's Evolving Relations with East Asia. London: Routledge. 2006.

Bilgin, Pinar and Adam David Morton. "Historicising Representations of 'Failed States': Beyond the Cold War Annexation of the Social Sciences?", dalam Third World Quarterly 23 No. 1. 2002.

Brown, Robin. "Information Technology and the Transformation of Diplomacy," in Knowledge, Technology, E Policy 18 No. 2. 2004.

Carment, David. "Assessing State Failure: Implications for Theory and Policy", dalam Third World Quarterly 24 No. 3. 2003.

Castells, Manuel. The Power of Identity, The Information Age, Economy, Society, and Culture. Blackwell Publishers. 1997.

CNN.com. "Exit Polls: Vote a repudiation of Bush, war in Iraq," accessed $8^{\text {th }}$ November 2006.

CNN.com. "Democrats look to sustain majority after anti-GOP wave," accessed on $12^{\text {th }}$ of November 2006.

Collinson, Stephen. "Clinton Promises 'Smart Power' Under Obama," in Associated Press 14 January 2009.

Crawford, Neta. “The Road to Global Empire: The Logic of U.S. Foreign Policy After 9/11," in Orbis 48 No. 4 p. 685-696. 2004.

Cumings, Bruce. "'Revising Postrevisionism,' or The Poverty of Theory in Diplomatic History", in Diplomatic History 17 No. 4. 1993.

Cumings, Bruce. "Still the American Century," in Review of International Studies 25; i 05 p.271-299. 1999.

Dorff, Robert H. “Failed States After 9/11: What Did We Know and What Have We Learned?", dalam International Studies Perspectives No. 6. 2005.

Farber, David. “Election '96: The American Electorate," an unpublished paper. 1996.

Hasenclever, Andreas, Peter Mayer and Volker Rittberger. Theories of International Regimes. Cambridge University Press. 1997.

Gourevitch, Peter. “Domestic and International Relations," in eds., Walter Carlsnes, Thomas Risse and Beth A. Simmons. Handbook of International Relations p. 309-328. Sage Publikations. 2005.

Huntington, Samuel P. American Ideals versus American Institutions," in G. J. Ikenberry, American Foreign Policy, Theoretical Essays. Third Edition. p. 221-254. New York: Longman. 1999

Ikenberry, G. John. "Liberal Hegemony and the Future of American Postwar Order", in eds., T.V. Paul and John A. Hall. International Order and the Future of World Politics. New York: Cambridge University Press. 1999.

Ikenberry, G. John. After Victory: Institutions, Strategic Restraint, and the Rebuilding of Order. Princeton N. J. : Princeton University Press. 2001. 
Ikenberry, G. John, (ed.). "The American Grand Strategy in the Age of Terror," in Survival 43 No. 4 p. 19-34. 2001-02.

Indyk, Martin S. Kenneth G. Lieberthal, and Michael C. O 'Hanlon. Bending History, Barack Obama's Foreign Policy. Washington DC: Brookings Institution Press. 2012.

Kohut, Andrew and Bruce Stokes. America Against the World. How We Are Different and Why We Are Disliked. New York Times Book. 2006.

Kurth, James. "Globalization and Empire: The Effects of 9/11 and the Iraq War," in eds., Bruce Mazlish et al. The Paradox of a Global USA. Stanford: Stanford University Press. 2007.

Lake, David A. Entangling Relations, American Foreign Policy in Its Century. Princeton: N. J. : Princeton University Press. 1999.

Lim, Merlyna. "Cyber-Civic Space in Indonesia. From Panopticon to Pandemonium?" in International Development Planning Review 24 No. 4 p. 383-400. 2002.

Mann, Michael. "The First Failed Empire of the $21^{\text {st }}$ Century", in Review of International Studies 30; i 04 p. 631-653. 2004.

Martin, Lisa L., and Beth A. Simmons. "Theories and Empirical Studies of International Institutions," in International Organization 52 No. 4. 1998.

Mauzy, Diane K. and Brian L. Job. "U.S. Policy in Southeast Asia. Limited Reengagement After Years of Benign Neglect", in Asian Survey XLVII No. 4. 2007.

Mazarr, Michael J. “The Iraq War and Agenda Setting”, in Foreign Policy Analysis No. 3, i 1.2007.

Mearsheimer, John J. “The False Promise of International Institutions," in International Security 19 No. 3. 1994/95.

Nanto, Dick K. “East Asian Regional Architecture: New Economic and Security Arrangements and US Policy", September 18, 2006 CRS Report for Congress RL33653. Congressional Research Service, The Library of Congress. 2006.

Phillips, Kevin. American Theocracy: The Peril and Politics of Radical Religion, Oil, and Borrowed Money in the 21 $1^{\text {st }}$ Century. New York: Viking. 2006.

PNAC. Rebuilding America's Defenses. 2000.

Rotberg, Robert I. (ed.). State Failure and State Weakness in a Time of Terror. Brookings Institution Press. 2003.

Transcript: 2003 State of the Union Address.

U. S. Department of Defense Annual Report to the Congress. Fiscal Year 1992. Washington D.C. January 1991: 131-2.

U.S. Department of Defense, A Strategic Framework for the Asian Pacific Rim: Looking Toward the 21 $1^{\text {st }}$ Century, 1990; A Strategic Framework for the Asian Pacific Rim, 1992; The East Asia Strategy Report, 1994; Report on Bilateral Defense Cooperation for the 21 ${ }^{\text {st }}$ Century, 1997; The United States Security Strategy for the East Asia-Pacific Region, 1998; Military Power of the People's Republik of China, Annual Report to Congress; The Quadrennial Defense Review, 
1997; 2001; 2006, 2010.

United States Under Secretary of Defense (policy). Asia 2025. Summer School Study Newport R.I.: U.S. Naval War College. 1999.

Vaughn, Bruce and Wayne M. Morrison. "China-Southeast Asia Relations: Trends, Issues, and Implications for the United States," Updated April 4, 2006 CRS Report for Congress RL32688. Congressional Research Service, The Library of Congress. 2006.

Weinstein, Franklin B. Indonesian Foreign Policy and The Dilemma of Dependence. From Sukarno to Soeharto. Ithaca: Cornell University Press. 1976.

Woo-Cumings, Meredith. unpublished manuscript., June 2004. 